Perpetrator groups can enhance their moral self-image by accepting their own intergroup apologies

\author{
Fiona Kate Barlow ${ }^{1}$, Michael Thai ${ }^{2}$, Michael J. A. Wohl ${ }^{3}$, \\ Sarah White, Marie-Ann Wright, and Matthew J. Hornsey²
}

1. School of Applied Psychology and Menzies Health Institute Queensland, Griffith University

2. School of Psychology, University of Queensland

3. Department of Psychology, Carleton University

Word Count: 8709 (excluding abstract, notes, references and tables)

Authors’ Note: The authors would like to thank Dr Roger Giner-Sorolla, as well as the two anonymous reviewers, for helpful comments and suggestions on earlier drafts of this manuscript. Please address all correspondences to Dr. Fiona Kate Barlow, School of Applied Psychology and Menzies Health Institute Queensland, Griffith University, Queensland, Australia. E-mail: f.barlow@griffith.edu.au. This project was supported by Australian Research Council Grants Awarded the first, third and last authors. 


\begin{abstract}
There is an implicit assumption that perpetrators' moral image restoration following an intergroup apology depends on absolution from victims. In this paper we examine whether perpetrators can in fact look to other ingroup members for moral pardon. In Studies 1 and 4, Australians read an apology to Indian people for a series of assaults on Indian nationals in Australia. In Studies 2 and 3, Non-Aboriginal Australians were provided with apologies offered on their behalf to Aboriginal Australians. In each study participants were told that other perpetrator group members had either accepted or rejected the apology. In line with predictions, when perpetrator group members heard that fellow perpetrators accepted an apology made to victims they felt morally restored, and consequently were more willing to reconcile. Effects were largely unqualified by apology quality (Studies 2-4), and held in the face of victim group apology rejection (Studies 3-4). We demonstrate that perpetrator group members can effectively gain moral redemption by accepting their own apologies, even qualified ones that have proved insufficient to victim groups.
\end{abstract}

KEYWORDS: Intergroup apologies, rejection, reconciliation, needs-based model of reconciliation, moral image 


\section{Perpetrator groups can enhance their moral self-image by accepting their own intergroup apologies}

Broadly, an apology is a communication in which an acknowledgement of responsibility and an expression of remorse is offered by an offending party to an offended party (Scher \& Darley, 1997; Tavuchis, 1991). Although much of the empirical work on apologies has been at the interpersonal level (see Exline, Baumeister, Bushman, Campbell, \& Finkel, 2004), a growing body of literature is now accumulating on the antecedents and consequences of collective apologies. Most of this work has focused on how collective apologies impact the victim group (see Hornsey \& Wohl, 2013, for a review). We suggest, however, that apologies are also crafted for an internal audience: other perpetrator group members. As such, it is important to understand how the responses of perpetrator group members to apologies offered on their behalf impact on their sense of themselves as a moral group, and consequently, their willingness to reconcile. This paper presents the first answers to these questions.

\section{The Needs-Based Model of Reconciliation}

Following a group-based transgression, histories remain fiercely contested, and members of perpetrator groups often resent, rather than welcome, efforts at reconciliation made on their behalf (Luke, 1997). Thus, knowing what drives perpetrator group members towards reconciliation is important, especially since they often hold (sometimes as a direct result of the historical transgression) the power, status, and financial sway to promote or prevent reconciliation efforts.

In order to understand intergroup reconciliation processes researchers have drawn on what we know about interpersonal transgression and reconciliation. Shnabel and Nadler’s (2008) needs-based model of reconciliation is one example from the interpersonal domain 
that has been successfully applied to the intergroup context. From this perspective, victims and perpetrators have different needs following an intergroup transgression. When people have been victimized they typically feel as if power, control, honor, and status have been stripped from them (Herman, 1992; Scheff, 1994). Perpetrators, on the other hand, are those who have taken power from the victim. Consequentially they often report feeling guilt (Doosje, Branscombe, Spears, \& Manstead, 1998; Leach, Iyer \& Pedersen, 2006), shame (Brown \& Čehajić, 2008; Brown, González, Zagefka, Manzi, \& Čehajić, 2008), and anxiety about their moral status as a group (Brown \& Čehajić, 2008; Exline \& Baumeister, 2000; McCullough, Worthington, \& Rachal, 1997; Tavuchis, 1991; for an overview of moral emotions see Giner-Sorolla, 2013).

With victim and perpetrator both suffering, Shnabel and Nadler (2008) see reconciliation as a social exchange through which both parties can have their needs met. For victims this is power, and for perpetrators, morality. Thus, Shnabel and colleagues (2009) propose that the primary goal of perpetrator groups in the process of reconciliation is to restore their public moral image, and it is the satisfaction of this need that promotes support for reconciliation efforts. Victim groups therefore hold power over the perpetrator group, as it is their acceptance that can cancel perpetrators’ moral debt.

\section{An Alternative Path to Perpetrator Moral Redemption}

But victim group members are not the only source of validation and social acceptance for perpetrators. In an intergroup transgression there are multiple social actors in both victim and perpetrator groups. This means that messages about acceptance and empowerment can come from the outgroup (as in Shnabel et al., 2009) or the ingroup. It is therefore theoretically possible that a perpetrator group could extend moral redemption to itself by accepting its own apology. 
It is often the case that the perpetrator group is a majority group, both in a numerical and a sociostructural sense. Thus, perpetrator group members may have limited contact with victim group members (Barlow, Louis, \& Hewstone, 2009), and therefore limited access to their responses to gestures of reconciliation. Additionally, victim groups are often afforded little voice, or do not make their responses to gestures of reconciliation public. On the other hand, during the reconciliation process perpetrator group members are likely to meet frequently, discussing, debating and responding to gestures of reconciliation made on their behalf (Luke, 1997). In this way, perpetrators may feel able to decide for themselves if moral redemption is warranted, given existing reconciliation efforts.

As detailed above, the needs-based model of reconciliation states that the way in which messages of social acceptance work to increase perpetrator group members' willingness to reconcile is through moral image restoration (although at the intergroup level this full path has never been tested). In this spirit, we suggest that perpetrator group members may be able to offer a message of acceptance to one another, feel morally restored as a result, and consequently be more willing to reconcile - all without reference to the victim group with whom they are hoping to reunite.

\section{Overview of Studies}

We test this proposal in four studies. Study 1 tests whether or not perpetrator group members feel morally restored and are consequently more willing to reconcile with the victim group if an intergroup apology offered to the victim group is accepted (relative to rejected) by fellow perpetrator group members. In Studies 2-4 we introduce apology quality as a potential moderator of the effect, examining whether it matters if perpetrator group members are rejecting or accepting qualified or unqualified apologies. In Studies 3-4 we also manipulate victim group apology acceptance or rejection, to test the robustness of our effects. Finally, in Study 4 we elucidate on why participants think perpetrators (as compared to victims) might 
reject a perpetrator-led apology. In doing so, we make the case that needs for moral rehabilitation can be partly met internally, such that perpetrator groups can offer an apology (unqualified or qualified), accept it themselves (even if it is rejected by victim group members), and consequently restore their own moral image (at least in their own eyes).

These studies make several contributions to the literature. First, although there is a burgeoning literature on the effects of intergroup apologies, it typically examines the effects of apologies on victim groups. Although this is obviously important, it is also true that the success of reconciliation attempts in part rests on the messages and resources offered by perpetrator groups. Accordingly, understanding the effects of apologies on perpetrator groups is of fundamental importance (Zaiser \& Giner-Sorolla, 2013). Second, the current studies shed light on the needs-based model of reconciliation (Shnabel \& Nadler, 2008), and the potential ways that perpetrator groups can fulfil these needs without the endorsement of victim groups. Finally, Studies 2-4 manipulate the quality of an intergroup apology to examine its downstream consequences. Although previous studies have examined aspects of the content of apologies (e.g., the emotional terms used: see Giner-Sorolla, Castano, Espinosa, \& Brown, 2008; Wohl, Hornsey, \& Bennett, 2012), few have done so in a way that implies that one is of higher quality than the other (for an exception see Zaiser \& GinerSorolla, 2013). Further, although the notion of qualified versus unqualified apologies has received attention in the literature on interpersonal transgressions (e.g., Benoit \& Drew, 1997; Hupka, Jung, \& Silverthorn, 1987; Ohbuchi \& Sato, 1994; Risen \& Gilovich, 2007), this is the first set of studies to examine its effects in the unique psychological domain of intergroup transgressions.

\section{Study 1}

In Study 1, non-Indian Australians (perpetrator group members) read about a real life intergroup transgression: the murder of an Indian student by an Australian teen. Note that this 
incident was described as explicitly intergroup, as there was speculation that the murder was racially motivated, and it occurred amid a huge increase in the frequency of attacks on Indians in Australia. Participants read an Australian Governmental apology to India (created for the purposes of this study), and were then given information about what percentage of fellow non-Indian Australians accepted or rejected the apology. Finally, participants' moral image and willingness to reconcile were measured. We proposed that participants who read that the apology was accepted by fellow perpetrator group members would feel more morally restored than when they read that it was rejected, and would consequently indicate a greater willingness to reconcile with Indian people.

\section{Method}

\section{Participants and Design}

Two hundred and one non-Indian Australian participants (107 women, 1 missing gender information) were recruited through an online data collection company $\left(M_{\text {age }}=46.65\right)$. Participants were randomly allocated to the conditions of a one-way between-groups design with two levels (perpetrator response: acceptance vs. rejection). Of the participants who completed the survey, 58 failed the manipulation check (detailed below), leaving a final sample of 143 (84 women, 1 missing gender information; $\left.M_{\mathrm{age}}=45.48\right)^{1}$.

Manipulations. All participants read a brief description of a real incident: the fatal stabbing of an Indian student by an Australian teen. The information highlighted the increasing number of Australian assaults against Indian nationals, as well as subsequent discussions between Australian and Indian ambassadors. Following this, participants read the text of an ostensibly real apology offered to India by a representative of the Australian Government. The apology was full and unqualified, with the representative offering a formal apology and expressing regret and sadness before stating: “As a nation, we take full responsibility for the series of attacks, and as a nation we need to engage in soul-searching 
about why this is happening. We need to consider the possibility that this goes beyond the actions of a few individuals; it is an issue that the whole country needs to accept responsibility for. Of course, we will also ensure we dedicate all the resources that are required to find the attackers and bring them to justice.” Following this, participants were presented with, again ostensibly real, information about how a sample of predominantly White Australians had responded to the apology. They saw two figures representing data, which they were told was collected by a (in reality, fictitious) research body called The Social Science Research Institute of Australia. The two figures represented the percentage of participants who had responded “yes”, "no” or "uncertain” to the statements: “I support the apology” and "I accept the apology made on my behalf”. In the acceptance condition approximately $70 \%$ of Australians were reported as replying “yes” to both statements, with approximately 70\% replying "no" to both statements in the rejection condition. After viewing the figures, participants completed the dependent measures.

\section{Measures}

Manipulation Check. Participants were asked whether perpetrator group members accepted or rejected the apology. Participants who answered incorrectly (e.g., answered either 'accept' or 'do not know' when they were in the rejection condition) were excluded from the dataset prior to analysis.

Moral image. Moral image was assessed with a 14-item scale (see Table 1 for all scales and response options used across Studies 1-4). Items 1-11 were adapted from Shnabel and Nadler's (2008) measure of moral image, and three novel items (items 12-14) tapped into how moral participants felt personally after reading the apology. Factor analysis of the items with varimax rotation revealed only one factor with an eigenvalue over 1 (eigenvalue $=10.28$, variance accounted for by the one factor solution $=73.43 \%$ ). Scores for these 14 items were averaged such that higher scores reflected a greater sense of moral image restoration $(\alpha=.97)$. 
Willingness to reconcile. Ten items were adapted from Shnabel and Nadler’s (2008) reconciliation scale $(\alpha=.96)$. Again, factor analysis of the items with varimax rotation revealed only one factor with an eigenvalue over 1 (eigenvalue=7.58, variance accounted for by the one factor solution $=75.75 \%$ ).

\section{Results and Discussion}

Effects of perpetrator group response emerged on both of our key outcome measures. Participants felt more morally restored when the perpetrator group accepted ( $M=4.29$, $S D=1.32)$ rather than rejected $(M=3.60, S D=1.44)$ the apology, $F(1,141)=8.72, p=.004$, $\eta_{\mathrm{p}}^{2}=.06$. Likewise, participants were more willing to reconcile after reading that the perpetrator group had accepted $(M=4.13, S D=1.59)$ rather than rejected $(M=3.54, S D=1.58)$ the apology, $F(1,141)=4.76, p=.031, \eta_{\mathrm{p}}^{2}=.03$.

\section{Mediation Analyses}

Regression analyses were used to test the indirect paths through which perpetrator response influenced willingness to reconcile (see Figure 1 for the full model and standardized regression coefficients). Tests of indirect effects based on 5000 bootstrapped samples revealed that participants who read that the apology was rejected rather than accepted felt less moral, and consequently less willing to reconcile ( $B=-.66, B_{S E}=.22 ; 95 \% C I=-1.09$ to -.22 ). The final model explained $68.69 \%$ (adjusted) of the variance in willingness to reconcile, $F(2,140)=156.79, p<.001$.

In sum, Study 1 presents strong support for our proposition that perpetrator group members can have their moral needs met by one another in the absence of a victim group response. Participants who read that fellow perpetrator group members accepted an apology offered on their behalf felt more moral than if it was rejected, and through this path were more willing to reconcile with the victim group. It should be noted, however, that the apology we presented in Study 1 was a "good" apology, in the sense that it included a complete 
admission of responsibility. The aim of Study 2 was to explore whether or not perpetrators could still draw moral restoration from fellow perpetrator group responses if the apology they were responding to was substandard, or qualified.

\section{Study 2}

When making an apology, transgressors are torn between two competing motivations. On one hand, there is the need for moral rehabilitation that Shnabel and colleagues (2009) argue perpetrator groups crave. On the other hand, there is a countervailing motivation to engage in identity protection; to temper or minimize the responsibility for the transgression. Indeed, many transgressor group members find it difficult to support reconciliation efforts because they are not ready to accept full responsibility for the events, because they feel the events were justified at the time, or because they are simply unwilling to let go of their own sense of victimhood in an intergroup conflict (Wohl, Hornsey, \& Philpot, 2011; see Noor, Shnabel, Halabi, \& Nadler, 2012, for a broader discussion of the notion of competitive victimhood). Consequently, perpetrators sometimes offer apologies that are tempered by explanations and excuses (e.g., "We acknowledge the transgression, but...”; Benoit, 1995).

Although perpetrators sometimes offer such apologies, they are typically unsatisfying to victims, and there is a general consensus in the literature that it is unqualified apologies that are preferred (Benoit \& Drew, 1997; Hupka et al., 1987; Ohbuchi \& Sato, 1994; Risen \& Gilovich, 2007). Given this, we might expect perpetrator group apology acceptance to increase perpetrator group members' moral image and willingness to reconcile only when a full and unqualified apology is offered. Conversely, if a qualified apology is offered it might be expected that any benefits of hearing about perpetrator group acceptance would be offset by the inadequacy of the responsibility-minimizing apology. We test these predictions in Study 2, while also changing the context of the apology to test whether our findings in Study 1 were generalizable. 
In 2008, newly elected Australian Prime Minister and the Leader of the Opposition both offered formal apologies on behalf of the government to Aboriginal Australians who had been forcibly removed from their families by the government in the $19^{\text {th }}$ and $20^{\text {th }}$ centuries (the Stolen Generations). In Study 2, the Stolen Generations represent the historical transgression, and non-Aboriginal Australians serve as the perpetrator group. As in Study 1, we exposed perpetrator group members to a qualified or an unqualified apology made on their behalf. We then led participants to believe that the majority of fellow perpetrator group members either accepted or rejected the apology. Our prediction for the mediated pathway was as per Study 1. As argued above, however, we hypothesized that this effect might only be present when the apology was full and unqualified.

\section{Method}

\section{Participants and Design}

Seventy-seven non-Aboriginal Australian undergraduates (49 women) participated in return for course credit $\left(M_{\mathrm{age}}=18.74\right)$. Participants were randomly allocated to the conditions of a 2 (apology quality: unqualified vs. qualified) x 2 (perpetrator response: acceptance vs. rejection) between-groups design.

Manipulations. In all conditions, a brief history of the Stolen Generations was provided. Participants were then given a half-page written apology for the Stolen Generations, which was attributed to a politician. Those in the unqualified apology condition were presented with an apology that read, in part: “...For the pain, suffering and hurt of these Stolen Generations, their descendants and for their families left behind, we say sorry. We apologize for the laws and policies of successive Parliaments and governments that have inflicted profound grief, suffering and loss on these our fellow Australians...” Those in the qualified apology condition read: "We formally offer an apology to those Aboriginal people forcibly removed from their families through the first seven decades of the twentieth 
century... Our generation does not own these actions, nor should it feel guilt for what was done in many, but not all cases, with the best of intentions...” ${ }^{2}$. After reading the texts, participants completed the questionnaire.

To manipulate perpetrator acceptance, participants were then presented with sketched images of three non-Aboriginal Australians, each paired with a quote. Depending on the condition, these quotes were manipulated such that they conveyed acceptance of the apology (e.g., "I applaud the (politician) for making the apology”) or rejection of the apology (e.g., “The (politician’s) apology was appalling”). Regardless of the manipulation, participants were told that the responses they read were typical of the reactions of non-Aboriginal Australians at the time. After reading the texts, participants completed the dependent measures.

\section{Measures}

Moral image $(\alpha=.93)$ and willingness to reconcile $(\alpha=.88)$ were measured as per Study 1, but changing the target outgroup from Indians to Aboriginal Australians (refer to Table 1).

\section{Results and Discussion}

Cell means and standard deviations are reported in Table 2. Participants who read an unqualified apology $(M=4.62)$ felt marginally more morally restored than those who read a qualified apology $(M=4.21), F(1,73)=3.01, p=.087, \eta_{p}^{2}=.04$. There was no significant main effect of apology quality on willingness to reconcile, however, $F(1,73)=.55, p=.460, \eta^{2}{ }_{p}=.01$. In line with Study 1, effects of perpetrator group response emerged on both of our outcome measures. Participants felt more morally restored when the perpetrator group accepted $(M=4.75)$ rather than rejected $(M=4.08)$ the apology, $F(1,73)=7.97, p=.006, \eta_{p}^{2}=.10$. Finally, participants were marginally more willing to reconcile after reading that the perpetrator group had accepted $(M=4.42)$ rather than rejected $(M=3.90)$ the apology, $F(1,73)=3.62, p=.061$, 
$\eta_{p}^{2}=.05$. In contrast to our predictions, however, there were no interactions between apology quality and perpetrator group response on either moral image or willingness to reconcile $(F \mathbf{s}<.90, p s>.346)$

\section{Mediation Analyses}

Regression analyses were used to test the indirect paths through which perpetrator response influences willingness to reconcile (see Figure 2 for the full model and standardized regression coefficients). Apology quality was included in the analyses as a covariate. Tests of indirect effects based on 5000 bootstrapped samples revealed that participants who read that the apology was rejected rather than accepted felt less moral, and consequently less willing to reconcile ( $B=-.44, B_{S E}=.17 ; 95 \% C I=-.80$ to -.12$)$. The final model explained $35.92 \%$ (adjusted) of the variance in willingness to reconcile, $F(3,73)=15.20, p<.001$.

In sum, participants who read that an apology offered on their behalf was rejected by fellow perpetrator group members felt less moral and through this path were less willing to reconcile with the victim group. In contrast to predictions, this process occurred independently of whether the apology was qualified or unqualified. Further to this, apology quality did not impact on participants’ willingness to reconcile, and an unqualified apology only led to marginally higher moral restoration than a qualified apology. As Shnabel and Nadler (2008) argue, perpetrators' damage primarily concerns excommunication from the moral community. Accordingly, they are motivated to look for social acceptance. On reflection then, our finding that perpetrator responses appeared to "trump" apology quality is not so surprising. Overall, Study 2 suggests that perpetrator groups can make a qualified apology, accept that apology, and achieve a degree of moral restoration in the process. A cynical interpretation of this is that perpetrator groups can effectively have a conversation with themselves that determines how they feel about an apology, and that potentially inconvenient victim voices are rendered irrelevant. To this point, however, we have not 
directly examined the influence of the victim group's voices in this process. Study 3 was designed to do so.

\section{Study 3}

In Study 3 we manipulated both the victim and perpetrator group’s responses to the apology, as well as apology quality. As described earlier, perpetrator group members often feel upset by their group’s transgression (Brown et al., 2008; Brown \& Čehajić, 2008; Doosje et al., 1998; Tavuchis, 1991). As such, they are highly motivated to seek out messages of social acceptance, and these acceptance messages are fundamental to whether the reconciliation process meets the emotional needs of the transgressor group (Shnabel et al., 2009). However, such messages are not always forthcoming. Perpetrators are keenly aware that victims may not be willing to forgive (Schönbach, 1990), and past work has shown that perpetrators can sometimes be reluctant to offer an apology if they anticipate its rejection (Leunissen, De Cremer, \& Reinders Folmer, 2012). Thus, we expect that when participants are told that an apology is accepted (compared to rejected) by victim group members, perpetrator group members will respond positively in terms of willingness to reconcile and associated constructs (as they did when they were told that other perpetrator group members accepted their apology).

In terms of higher order interactions, we identified several possibilities. First, it was possible that responses would be additive, such that apologies that were universally accepted (by both victim and perpetrator group members) would restore moral image the best, and increase willingness to reconcile the most. If this were the case, the reverse would be expected for apologies that were universally rejected; that is, moral image restoration and reconciliation intentions would be lowest when both the victim and perpetrator groups rejected the apology. Furthermore, one would expect responses to mixed messages (e.g., victim acceptance combined with perpetrator rejection, or vice versa) to sit between these 
extremes. An alternative possibility is that one set of responses would trump the other; for example that victim group rejection would cancel out any gains from perpetrator acceptance, and vice versa. Given that apologies are specifically offered to victim groups, it might be supposed that it is their responses that will carry the most weight.

Our design also allows us to again test whether the effects of victim group rejection are moderated by the objective quality of the apology (i.e., qualified versus unqualified). While we did not find any moderation in Study 2, the introduction of victim group response allows us to see whether victim group apology rejection still leads to reduced willingness to reconcile if victim group members are rejecting a substandard apology.

Finally, in this study we consider a new mediator. As discussed earlier, Shnabel and colleagues (2009) propose that messages of social acceptance increase perpetrator group members' willingness to reconcile with the victim group as a result of public moral image restoration. But an alternative pathway is also possible. In general, people are extremely sensitive to rejection from outgroup members (see Barlow et al., 2009; Barlow, Louis, \& Terry, 2010; Barlow, Sibley, \& Hornsey, 2012), and rejection of reconciliation attempts can lead to hostile evaluations of victim group members (Harth, Hornsey, \& Barlow, 2011). Further, work on negative intergroup contact demonstrates that negative interpersonal interactions can generalize to and inform attitudes about the outgroup (Alperin, Hornsey, Hayward, Diedrichs, \& Barlow, 2015; Barlow et al., 2012; Techakesari et al., 2015). Thus, it is possible participants will evaluate victim group apology rejecters negatively, and that this will translate into decreased willingness to reconcile. Such an assertion is consistent with recent work showing that acceptance from victims increases the extent to which perpetrators trust them (Shnabel, Nadler, \& Dovidio, 2014). Although we measure evaluations of both victim and perpetrator group rejecters, we would not expect evaluations of perpetrator group rejecters to be associated with a willingness to reconcile with the victim group. 


\section{Method}

\section{Participants and Design}

The sample comprised 128 non-Indigenous Australian undergraduates (85 female) who participated in return for course credit $\left(M_{\mathrm{age}}=21.17\right)$. Participants were randomly allocated to the cells of a 2 (apology quality: unqualified vs. qualified) x 2 (victim response: acceptance vs. rejection) x 2 (perpetrator response: acceptance vs. rejection) between-groups design.

Procedure and Measures

The procedure was the same as that used in Study 2, with the exception that we manipulated both victim and perpetrator acceptance. Moral image $(\alpha=.87)$ and willingness to reconcile $(\alpha=.87)$ were measured as in Studies 1 and 2. Evaluation of victim/perpetrator responders was measured through three items per group (refer to Table 1 ; $\alpha$ s both $=.83$ ). Means and standard deviations are summarized in Table 3.

\section{Results}

Moral image. In line with results from Study 2, participants who read the unqualified apology ( $M=4.64)$ felt significantly more morally restored than those who read the qualified apology $(M=4.11), F(1,120)=9.16, p=.003, \eta_{p}^{2}=.07$. Main effects of victim group, $F(1,120)=11.03, p=.001, \eta_{p}^{2}=.08$, and perpetrator group response, $F(1,120)=12.18, p=.001$, $\eta_{\mathrm{p}}^{2}=.09$, also emerged. Participants felt more morally restored when the apology was accepted $(M=4.66)$ rather than rejected $(M=4.08)$ by the victim group, as well as when it was accepted $(M=4.68)$ compared to rejected $(M=4.07)$ by the perpetrator group. This time, however, the effect of perpetrator response was moderated by whether the apology was qualified or not, $F(1,120)=5.47, p=.021, \eta^{2}=.04$. Follow-up analyses revealed that the tendency for there to be greater moral restoration when the apology was accepted $(M=4.62)$ compared to rejected $(M=3.60, p<.001)$ only emerged when the apology was qualified. When 
the apology was unqualified it did not matter whether perpetrators accepted $(M=4.74)$ or rejected $(M=4.54, p=.414)$ the apology.

Finally, there was a significant interaction between perpetrator and victim group response, $F(1,120)=4.38, p=.039, \eta_{\mathrm{p}}^{2}=.04$. When perpetrator group members accepted the apology, participants felt less morally restored if victim group members rejected $(M=4.21)$ rather than accepted the apology $(M=5.15, p<.001)$. If perpetrator group members rejected the apology, however, it did not matter whether victim group members rejected $(M=3.96)$ or accepted $(M=4.18, p=.394)$ the apology. No further significant two or three-way interactions emerged, $F \mathbf{s}<.86, p s>.357$.

Evaluation of victim responders. As expected, victim group responders were evaluated more positively when they accepted $(M=5.57)$ than when they rejected $(M=4.40)$ the apology, $F(1,120)=36.89, p<.001, \eta_{p}^{2}=.24^{3}$.

Evaluation of perpetrator responders. Perpetrator group responders were also evaluated more positively when they accepted $(M=5.10)$ as opposed to rejected $(M=3.73)$ the apology, $F(1,119)=42.24, p<.001, \eta_{p}^{2}=.26^{4}$.

Willingness to reconcile. Main effects of victim group response, $F(1,120)=21.36, p<.001, \eta_{p}^{2}=.15$, and perpetrator group response, $F(1,120)=5.92, p=.016$, $\eta_{p}^{2}=.05$, emerged on willingness to reconcile. Participants felt greater willingness to reconcile when the apology was accepted $(M=4.75)$ rather than rejected $(M=3.88)$ by victim group members. They were also more willing to reconcile when perpetrators accepted $(M=4.55)$ rather than rejected $(M=4.09)$ the apology. No other main or interaction effects emerged, $F \mathbf{s}<1.86$, all $p s>.175$.

Mediation Analyses

Figure 3 summarizes a similar model to that tested in Studies 1 and 2, but this time with victim and perpetrator response entered simultaneously, and the addition of evaluations 
of victim and perpetrator group responders as potential mediators. Both moral image and evaluations of the victim group responders predicted willingness to reconcile. Evaluation of perpetrator group responders was unrelated to willingness to reconcile, so no indirect effects through evaluations of perpetrator acceptance were tested. As per Study 2, apology quality was included in the analyses as a covariate.

Results based on 5000 bootstrapped samples revealed that victim group acceptance had a significant indirect effect on willingness to reconcile through both mediators.

Consistent with the needs-based model of reconciliation, when the apology was accepted by the victim group, participants felt more moral, and consequently more willing to reconcile, than when the victim group rejected the apology ( $B=-.34, B_{S E}=.12 ; 95 \% C I=-.59$ to -.13$)$. In parallel, when the apology was rejected by the victim group, participants were more negative about the victim group responders, and through this were less willing to reconcile $(B=-.25$, $B_{S E}=.10 ; 95 \% C I=-.45$ to -.07$)$. As in Study 2, participants who read that the apology was accepted by the perpetrator group also felt more moral and consequently more willing to reconcile ( $B=-.35, B_{S E}=.11$; $95 \% C I=-.59$ to -.13 ). The final model explained $45.78 \%$ (adjusted) of the variance in willingness to reconcile, $F(6,120)=18.73, p<.001$.

\section{Discussion}

The results of Study 3 largely mirrored those of Study 2. In line with our hypotheses, the positivity of participants' moral image was enhanced when the apology was accepted, but this time regardless of whether acceptance was by victim or perpetrator group members. That is, there were main effects of both perpetrator and victim group responses to the apology. Unlike in Study 2, in Study 3 we were able to examine what happened when perpetrator and victim groups competed (i.e., one accepted and the other rejected the apology). Before conducting Study 3 we identified several possibilities in terms of how the two might interact. Specifically, we thought that either responses would have an additive effect (e.g., with 
rejection from one group dulling the effects of acceptance from the other), or, given that it is victims to whom apologies are offered, the victim group responses would trump perpetrator group responses. On moral image, at least, our data implied a pattern in line with the first of the two possibilities we identified: rejection from one group cancelled out acceptance from another. Thus, the only boost to moral image was observed when both the victim and the perpetrator groups accepted the apology. This interaction was not evident, however, when it came to willingness to reconcile. Overall then, we found no evidence that victim group responses were somehow more meaningful to perpetrators

In line with our hypotheses, when it came to how acceptance promoted reconciliation, the pattern was different for perpetrator vs. victim group acceptance. When participants believed fellow perpetrator group members rejected the apology they felt less moral, and subsequently less willing to reconcile. The same was true when they believed victim group members rejected the apology, but an additional mediator came into play. Specifically, participants negatively evaluated victim group members who rejected (compared to accepted) the apology, and consequently reported less enthusiasm for, and commitment to, reconciliation efforts.

As in the previous studies, the quality of the apology played a surprisingly small role in moderating the effects of acceptance versus rejection. The negative consequences of victim group rejection - on both attitudes toward reconciliation and toward the victim group members themselves - emerged independently of whether the apology was an objectively “good” or "bad” one. For perpetrator group responses, there was some moderation by apology quality: the power of perpetrator group acceptance to foster their own moral rehabilitation was only evident when the apology was qualified (although note that this pattern was not evident in Study 2). Examination of means reveal that moral image is 
relatively high for perpetrator group members in all cases but those in which an apology is “bad” (qualified) and rejected by fellow perpetrator group members.

At this point, several questions remain. First, in Studies 1-3 we did not specify whether perpetrator (or victim) group responses to the apology were made public. Thus far we have built a theoretical case around perpetrator group acceptance (like victim group acceptance) being innately morally restoring. An alternative possibility is that participants may have believed that perpetrator group members' responses to the apology were made public, thus conveying a moral message directly to the international community. To ensure this was not the case in Study 4 we made it explicit that the responses were not public messages. Further to this, in Study 3 both victim and perpetrator rejection impaired perpetrator group members' moral image. It does not follow, however, that participants believed that victim and perpetrator group members were rejecting the apologies for the same reasons. Thus, Study 4 was designed to replicate Study 3 while elaborating on the different attributions participants made for perpetrator vs. victim apology rejection.

\section{Study 4}

In Study 4 we reverted back to the context used in of Study 1: assaults on Indians by Australians. We also made explicit that all responses to the apology had not been seen by anyone other than the researchers who ostensibly collected the data. Hypotheses were as per Study 3. An additional goal of Study 4 was to find out why participants thought that others rejected their apologies. There are two broad reasons why someone might fail to support an apology: because it is too much (in the sense that they feel a full apology is not necessary) or because it is too little (e.g., because they feel the apology obfuscates, excuses or diminishes the transgression). In Studies 1-3 we based our model on the assumption that participants would presume victims rejected the apology because they thought it was too little, and that 
perpetrators rejected the apology because they thought it was too much. In Study 4 we tested this assumption directly.

\section{Method}

\section{Participants and Design}

Non-Indian Australian participants ( $N=393 ; 51.4 \%$ women) were recruited through an online data collection company $\left(M_{\text {age }}=48.31\right)$. Participants were randomly allocated to the cells of a 2 (apology quality: unqualified vs. qualified) x 2 (victim response: acceptance vs. rejection) x 2 (perpetrator response: acceptance vs. rejection) between-groups design. Of the participants who completed the survey, 146 failed either the manipulation or attention check (detailed below), leaving a final sample of 247 (51.8\% women; $M_{\text {age }}=48.05$ ).

Procedure

The procedure was the same as that used in Study 3, but drawing on the context of Study 1. The unqualified apology was the same as that used in Study 1. For the qualified apology the government representative also offered a formal apology, and expressed sadness and regret, but then stated: "As a nation we feel as though this issue is the result of the actions of a few individuals. It is those individuals who need to accept responsibility for what has happened and engage in soul-searching about the harm it has caused. Of course, we will also ensure we dedicate all the resources that are required to find the attackers and bring them to justice”. Additional measures were included (see the measures section).

\section{Measures}

Moral image $(\alpha=.94)$ and willingness to reconcile $(\alpha=.93)$ were measured as in Studies 1-3. Evaluation of responders were measured as per Study 3 ( $\alpha=.60$ for perpetrator evaluations and $\alpha=.62$ for victim evaluations). New measures were included, but employed only when participants read that Indians and/or Australians had rejected the apology (see Table 1). Items were averaged to form two scales: Perceived reasons for Indian rejection 
$(\alpha=.77)$ and Perceived reasons for Australian rejection $(\alpha=.87)$. In each case, a high score indicated that participants thought responders rejected the apology because it was too much, with a low score indicating that participants thought that responders rejected the apology because it was too little. Means and standard deviations are summarized in Table 4

\section{Results and Discussion}

Moral image. In line with Studies 2 and 3, participants who read the unqualified apology $(M=4.13)$ felt marginally more morally restored than those who read the qualified apology $(M=3.88), F(1,239)=3.55, p=.061, \eta_{p}^{2}=.02$. Main effects of victim group, $F(1,239)=20.01, p<.001, \eta_{p}^{2}=.08$, and perpetrator group response, $F(1,239)=10.33, p=.001$, $\eta_{\mathrm{p}}^{2}=.04$, also emerged. Participants felt more morally restored when the apology was accepted $(M=4.31)$ rather than rejected $(M=3.70)$ by the victim group, or accepted $(M=4.23)$ rather than rejected $(M=3.79)$ by the perpetrator group. In contrast to Study 3, there were no significant two or three way interactions, all $F_{\mathbf{s}}<2.18, p s>.141$.

Evaluation of victim responders. Again, victim group responders were evaluated more positively when they accepted $(M=4.87)$ than when they rejected $(M=4.52)$ the apology, $F(1,239)=8.03, p=.005, \eta^{2}=.03^{5}$.

Evaluation of perpetrator responders. Perpetrator-group responders were also evaluated more positively when they accepted $(M=4.80)$ as opposed to rejected $(M=4.48)$ the apology, $F(1,239)=6.70, p=.010, \eta^{2}=.03^{6}$.

Willingness to reconcile. A main effect of victim response emerged on willingness to reconcile, $F(1,239)=4.32, p=.039, \eta_{\mathrm{p}}^{2}=.02$. Participants felt greater willingness to reconcile when the apology was accepted $(M=4.29)$ by the victim group than when it was rejected $(M=3.95)$. As in Studies 1-3 willingness to reconcile was higher when perpetrator groups accepted $(M=4.22)$ rather than rejected $(M=4.02)$ the apology, although this time the 
difference failed to reach significance, $F(1,239)=1.51, p=.221, \eta^{2}=.01$. No other main or interaction effects emerged, all $F \mathbf{s}<2.15$, all $p s>.144$.

\section{Mediation Analyses}

Figure 4 summarizes the same model tested in Study 3, in the new context. Both moral image and evaluations of the victim group responders predicted willingness to reconcile. Evaluation of perpetrator group responders was unrelated to willingness to reconcile, so no indirect effects through evaluations of perpetrator acceptance were tested. As in Studies 2 and 3 apology quality was included in the analyses as a covariate.

Results based on 5000 bootstrapped samples revealed that victim group acceptance had a significant indirect effect on willingness to reconcile through both mediators. As in Study 3, when the apology was accepted by the victim group, participants felt more moral, and consequently more willing to reconcile, than when the victim group rejected the apology ( $B=-.41, B_{S E}=.10 ; 95 \% C I=-.61$ to -.23 ). In parallel, when the apology was rejected by the victim group, participants were more negative about the victim group responders, and through this were less willing to reconcile ( $B=-.22, B_{S E}=.08$; $95 \% C I=-.38$ to -.07$)$. While perpetrator group acceptance did not directly predict willingness to reconcile, we could still test for indirect effects through moral image (see Hayes, 2009). As in Studies 1-3, participants who read that the apology was accepted by the perpetrator group also felt more moral and consequently more willing to reconcile ( $B=-.30, B_{S E}=.10 ; 95 \% C I=-.49$ to -.11 ). The final model explained 59.88\% (adjusted) of the variance in willingness to reconcile, $F(6,238)=61.69, p<.001$.

Perceived Reasons for Apology Rejection

In Study 4 we asked participants why they thought Indian or Australian people rejected the apology; was it because the apology was too much, or not enough? Note that not all participants were exposed to an apology rejection, and thus we cannot test the full model 
predicting attributions for rejection. Instead we tested the means for Indian and Australian rejection attributions against the scale midpoint (4). Consistent with our assumptions in Studies 1-3, participants generally thought that Indian people rejected the apology because it was too little $(M=3.19, t(123)=-8.83, p<.001,95 \% C I=-.99$ to -.63$)$. In contrast, they thought that Australians generally rejected the apology because it was too much ( $M=4.38$, $t(120)=2.98, p=.003,95 \% C I=.13$ to .64$)$. Apology quality did not impact on why participants thought either victims or perpetrator group members rejected the apology (Fs $<1.26, p s>.264)$. It did matter, however, whether participants were told that the other group accepted or rejected the apology. The tendency to think that victims rejected the apology because it was too little was more pronounced when perpetrators also rejected the apology $(M=3.01)$ compared to when perpetrators accepted the apology $(M=3.40)$, $F(1,124)=4.67, p=.033, \eta_{p}^{2}=.04$. Conversely, the tendency to think that perpetrators rejected the apology because it was too much was more pronounced when victims accepted the apology $(M=4.71)$ compared to when victims rejected the apology $(M=4.14), F(1,118)=4.95$, $\left.p=.028, \eta_{\mathrm{p}}^{2}=.04\right)$. The main message from these analyses, however, is that attributions were in line with the assumptions made in Studies 1-3. In addition, Study 4 replicates the core mediational pathway presented in this paper, while ensuring that participants believed that all responses to apology were private.

\section{General Discussion}

Perpetrator group members have the power to respond to apologies made on their behalf, and in this paper we make the case that such responses influence the extent to which perpetrators feel their moral image has been enhanced. In line with the needs-based model, we argued that such moral image enhancement would have flow-on effects for perpetrators willingness to reconcile with victims. Over four studies, we show that this is indeed the case. When perpetrators heard that fellow perpetrators accepted (rather than rejected) an apology 
made to victims they felt morally restored, and were consequently more willing to reconcile. Interestingly, moral restoration occurred largely irrespective of whether the apology offered was substandard (Studies 2-4), or whether the victim group rejected the apology (Study 4; although the impact of perpetrator response was moderated by victim group response in Study 3). Such a pattern flies in the face of traditional conceptualizations of the reconciliation process; it shows that perpetrator group members have the capacity to meet their moral needs internally, with limited reference to the victim group that they have harmed.

Further, in Studies 3 and 4, we observed that victim group members who rejected an apology face a backlash from perpetrators. Specifically, victim group members who rejected an apology were disliked compared to those who accepted them (see also Harth et al., 2011). This derogation of victim group members who rejected the apology emerged independently of whether the apology was qualified (and thus objectively more likely to invite rejection) or unqualified. These findings demonstrate that, like individual victims (Bennett \& Dewberry, 1994), victim group members who reject apologies do so at a personal cost. Furthermore, this personal cost quickly translates to the intergroup level, with negative evaluations of victim group responders predicting lower levels of willingness to reconcile among perpetrator group members.

Implications for the needs-based model of reconciliation. A plausible response to feeling morally tarnished (e.g., because the victim group has rejected your group’s apology) is to increase your attempts to achieve reconciliation. However, a striking aspect of the current data is that the reverse is true: When participants could not achieve the moral rehabilitation they were looking for, this was associated with a decrease in reconciliation intentions. This effect is perfectly in line with the needs-based model of reconciliation (Shnabel \& Nadler, 2008; Shnabel et al., 2009), which argues that messages of acceptance from victim groups will increase perpetrators' willingness to reconcile by meeting the 
emotional needs that have been depleted through the transgression. Specifically, they argue that perpetrator groups feel that their group is no longer publicly recognized as moral or acceptable in the eyes of others. It is a message of social acceptance, they suggest, that will allow perpetrator group members to feel morally restored, and this draws them towards engaging in future acts of reconciliation. While this full process has been tested in interpersonal transgressions (Shnabel \& Nadler, 2008), we are the first to test the full mediational model at the intergroup level.

We also revealed an additional mediator of the effect, arguing that participants should dislike apology rejecters (in line with Shnabel et al., 2014), and that this dislike should influence their willingness to reconcile. Because negative evaluations of individual outgroup members are especially likely to be generalized to the outgroup as a whole (Barlow et al., 2012), it was the dislike of victim group rejecters specifically that we suggested should predict a decreased willingness to reconcile with the victim group. Our findings supported this hypothesis. Given that willingness to reconcile with the victim group is less related to how individual perpetrator group members are evaluated, we did not expect (nor did we find) that dislike of perpetrator group rejecters predicted willingness to reconcile. This asymmetry is interesting, and perhaps speaks to the broader way in which we engage with ingroups and outgroups. For example, outgroups are typically seen as more homogeneous than are ingroups (Park \& Rothbart, 1982). Although it is theoretically possible that those who grow to dislike their own group may attempt to affiliate with outgroups (and so be more willing to reconcile with the victim outgroups), it is unlikely that negative evaluations of a subsection of ingroup members would generalize to dislike of the larger ingroup.

Another contribution to the needs-based model of reconciliation is the realization that the social acceptance that perpetrator groups desire can in part be obtained in house; that is, by accepting their own apologies (even sub-standard ones). Previously it has been assumed 
that enhancement of one's moral image can only be achieved through acceptance from victim groups and/or relevant third parties. But our work shows that one's moral image can actually be bolstered by supportive messages from fellow perpetrator group members. This is not to say that the voices of victims do not matter: Study 3 suggests that victim voices are important, and in fact can alter how morally restoring perpetrator acceptance is. In Study 4, while we failed to find a direct effect of perpetrator responses to apology on willingness to reconcile, victim acceptance relative to rejection significantly promoted reconciliation. This is reassuring because it diminishes the notion that the reconciliation process is entirely a conversation that perpetrator groups can have with themselves.

Interestingly, while the impact of victim group rejection largely mirrored that of perpetrator group rejection, Study 4 revealed that the attributions participants made about why victims and perpetrators rejected apologies were very different. Participants generally thought that victim group members rejected an apology because they found it insufficient, or too little, whereas perpetrators rejected an apology because they found it too much or too strong. In each case, the objective quality of the apology simply did not matter: rejection itself appeared to trigger participants’ assumptions about each group’s motives, regardless of whether the apology was qualified or unqualified. Overall, these assumptions appeared to be: “victims want more, perpetrators want to do less”. Irrespective of these differing attributions, however, both victim and perpetrator rejection impacted upon moral image and willingness to reconcile in a similar way. These results suggest that, regardless of apology quality, an apology accepted by both victim and perpetrator groups may be perceived as optimal in meeting the needs of both groups (i.e., not too little for victims, not too much for perpetrators), and this is what facilitates moral restoration.

In terms of which reaction is going to be more impactful, we can see that when confronted by both victim and perpetrator responses to apology, both are heeded. Past work, 
however, has shown that in general we pay special attention to what our ingroup thinks, feels and does (e.g., Jetten, Spears, \& Manstead, 1996). For a perpetrator group, then, feedback from one's own group may be more salient (and accessible) than feedback from the victim group. In the face of any symbolic gesture of reconciliation, it is likely that there will be a mixture of responses from the victim group, ranging from highly supportive to highly rejecting. It is possible that in this case perpetrator group members will be motivated to turn to ingroup messages of acceptance, rather than dealing with ambiguous victim group responses.

This leads to an important question: does it matter where acceptance comes from? In terms of justice, the answer is a definitive yes. Perpetrator groups do not have the ability, or license, to speak accurately for victim groups. Reconciliation is inherently an intergroup, not intragroup process. On the other hand, there are pragmatic benefits to self-forgiveness. At an interpersonal level, for example, self-forgiveness can help to restore perpetrators' sense of morality, and consequently has a positive impact on reconciliation (Wohl \& McLaughlin, 2014; Woodyatt \& Wenzel, 2014).

Implications for our understanding of apology quality. As discussed above, the vast majority of the effects of acceptance and rejection emerged independent of apology quality. Given that unqualified apologies are universally preferred by victims (Benoit \& Drew, 1997; Hupka et al., 1987; Ohbuchi \& Sato, 1994; Risen \& Gilovich, 2007), we initially expected perpetrators to respond more positively to unqualified apologies. In particular, we suspected that perpetrator group acceptance might only have a positive impact on perpetrator group members if they read that their own group had offered an unqualified apology. Conversely, we thought that a qualified apology might undermine the morally restorative effects of fellow perpetrator acceptance. In contrast to our predictions, while some moderated effects appeared, they were not consistent across studies. Further, although perpetrator group 
members felt more morally restored by an unqualified apology, this did not translate into an increased willingness to reconcile.

If we look to Shnabel and colleagues' (2009) theorizing, our findings are perhaps understandable. Historical transgressions hurt perpetrators as well as victims. Perpetrators crave social acceptance, and while apology quality might affect the extent to which participants feel morally restored, it does not do the job as well as having the apology accepted. Overall our results suggest that in contrast to victims, perpetrators may be less sensitive to the quality of an intergroup apology. It is also possible that perpetrators are conflicted by competing drives when assessing group based apologies. The recognition that an unqualified apology will be more acceptable to victims might be offset by a desire to excuse the transgression (Benoit, 1995), or retain a sense of victimhood themselves (Noor et al., 2012; Wohl et al., 2011). Future research should test these possibilities.

\section{Strengths, Limitations, and Future Directions}

A strength of the current paper is that we focused on the attitudes of perpetrator groups toward an apology. Traditionally, the collective apology literature has focused on the impact of an apology on the victim group. But the response of perpetrator groups is also important, both politically and psychologically, not least because it sends signals to the victim group about the authenticity of the apology (see Zaiser \& Giner-Sorolla, 2013, for what we believe is the only other paper examining this question). However, the exclusive focus on perpetrators does raise the question of how victim groups would respond to the same manipulations. For example, while victim group acceptance of a qualified apology was satisfying to perpetrator group members, it is possible that perpetrator group acceptance of a qualified apology would be insulting and/or damaging to victim group members. The effect on victims of victim and perpetrator group responses to collective apologies warrants future research attention. 
A further strength of this paper is that it is one of the first to examine the impact of the quality of an intergroup apology on the reconciliation process (see also Zaiser \& GinerSorolla, 2013). In doing so, we focused on whether the apology is qualified or unqualified. But apologies and other gestures of reconciliation can vary in many other ways. For example, in the interpersonal literature brief apologies are less successful in winning forgiveness than detailed apologies (Darby \& Schlenker, 1982). It is possible that perpetrator group members are more sensitive to other aspects of apologies, some of which may be more innately suited to moral restoration and subsequent willingness to reconcile. Future research should explore these possibilities.

In our studies we drew on real-life intergroup transgressions. It is beneficial to examine the dynamics of real-world apologies in real-world settings, because they are captured by different psychological dynamics than transgressions that are confected in the laboratory (Hornsey \& Wohl, 2013). In the future, though, it will be important to examine our model looking at different types of transgressions. The intergroup transgressions we used are severe but contested; that is, there are still debates about the intentions of transgressors and the degree to which perpetrator group members should accept responsibility. It remains to be seen what would emerge if transgressions were unambiguous and acknowledged by perpetrator group members. In such settings, perpetrators (as well as victims) might demand an unqualified apology, and only receive moral restoration following ingroup acceptance of an unqualified apology. In sum, while our effects held over two real-world contexts, it will be ideal to test the robustness of our effects across a range of social situations and intergroup transgressions.

Finally, we focused on victimized and perpetrator group acceptance because they are the variables that seem most central to the reasoning of the needs-based model of reconciliation. However, apologies have multiple audiences, and a key audience includes 
third parties (i.e., groups that are witnesses to transgressions, but neither perpetrators nor victims). While work from the interpersonal domain suggests third party responses are insufficient to restore perpetrators' moral image (Shnabel et al., 2014), it would be interesting to see whether intergroup acceptance from a third party (e.g., the UN, an unrelated group or country) might serve the same purpose as acceptance from either victimized or perpetrator groups.

\section{Conclusion}

Reconciliation is not easy, and both perpetrator and victim groups need to have the will to work for it. In line with past research we find that one factor critical to driving perpetrator group members towards reconciliation is social acceptance (in our case, acceptance of a collective apology; Shnabel et al., 2009). But acceptance need not necessarily come from the victim group, nor must it be in response to a full and unqualified reconciliation attempt. Instead, it is any acceptance that clears the slate of perpetrator group members' collective consciences, and subsequently drives them towards reconciliation. As such, we show that it is possible for perpetrator group members to craft an apology, respond to it themselves, and consequently award themselves group-based absolution for transgressions. 


\section{Notes}

${ }^{1}$ In Studies 1-4 all manipulations are reported. In each study we aimed for a minimum sample size of 20-30 participants per cell (achieving this in all but Study 3). We aimed to oversample in Studies 1 and 4 to compensate for the online nature of data collection, and potential failure of participants to pay attention (see deletion details for manipulation and attention check fails). Studies 2 and 3 were conducted in the laboratory by research experience/honors students (all of whom are authors on this paper). The sample size for these studies was limited by their availability at the time, and the requirements of their courses. In Study 1 we collected half the sample first, in order to assess the rate of manipulation check failure, and then recruited the remainder of the sample. For Studies 2-4 we did not add any participants after viewing the data. Studies 2 and 3 also featured questions pertaining to an unrelated set of research questions about intergroup contact, meta-cognitions and prejudice. Study 4 contained questions about apology strength not relevant to the current paper. Data for these questions are not reported here or in any other paper submitted for publication.

${ }^{2}$ We conducted a pilot study to test whether or not the manipulation of apology quality was appropriate. Non-Aboriginal Australians were recruited online via a snowballing technique through e-mail and social networking sites. The final sample comprised 95 non-Aboriginal Australians (59 female). Ages ranged from 18 to $84\left(M_{\text {age }}=41.00\right)$. Participants were randomly assigned to either the qualified or unqualified apology conditions. Consistent with the manipulation, participants saw the qualified apology to be exonerating Australians of responsibility more than the unqualified apology, $F(1,90)=7.88, p=.006, \eta_{\mathrm{p}}^{2}=.08$. Australians also recognized the downsides of this type of apology: participants expected that Aboriginal Australians would accept the unqualified apology significantly more than the qualified apology, $F(1,90)=15.16, p<.001, \eta_{p}^{2}=.14$. 
${ }^{3}$ In the interests of transparency we note that this effect was qualified by an interaction with perpetrator group response, $F(1,120)=2.90, p=.091, \eta_{p}^{2}=.02$. In general, when perpetrator group members accepted the apology, victim group members who also accepted $(M=5.66)$ the apology were liked much more than those who rejected $(M=4.15, p<.001)$ it. When perpetrator group members rejected the apology victim group members who accepted $(M=5.49)$ the apology were still liked more than those who rejected $(M=4.64, p=.003)$ it, although this difference was somewhat smaller. This moderated relationship was not theorized, nor was is theoretically relevant to the current paper. No additional main or interaction effects emerged, $F \mathrm{~s}<1.88, p \mathrm{~s}>.173$.

${ }^{4}$ The main effect of perpetrator response on evaluations of perpetrators was qualified by a significant interaction with victim acceptance, $F(1,119)=17.56, p<.001, \eta^{2}=.13$. Tests of simple effects revealed that when the apology was accepted by the victim group, participants liked the perpetrator group responders significantly more when they also accepted $(M=5.69)$ rather than rejected it $(M=4.51, p<.001)$. When the apology was rejected by the victim group, however, it did not matter whether perpetrators accepted $(M=3.44)$ or rejected $(M=4.03$, $p=.110$ ) the apology. As perpetrator group evaluations are simply included in the model to demonstrate that it is evaluations of victims, not perpetrators, that influence willingness to reconcile, this effect will not be discussed further. No other main or interaction effects emerged, all Fs<1.97, ps>.163.

${ }^{5}$ As in Study 3 this effect was moderated by perpetrator group response $F(1,239)=3.83$, $p=.051, \eta_{\mathrm{p}}^{2}=.02$. This time, when perpetrators accepted the apology victim group members who also accepted $(M=4.98)$ the apology were liked more than those who rejected $(M=4.39$, $p=.001)$ it. When perpetrator groups rejected the apology, however, victims who accepted $(M=4.76)$ or rejected $(M=4.66, p=.543)$ the apology were liked equally. No additional main or interaction effects emerged, $F \mathbf{s}<2.54, p s>.112$. 
${ }^{6}$ As in Study 3 the main effect of perpetrator response was qualified by a significant interaction with victim response, $F(1,239)=7.27, p=.007, \eta_{p}^{2}=.03$. When the apology was accepted by the victim group, participants liked the perpetrator group responders significantly more when they also accepted $(M=5.00)$ rather than rejected it $(M=4.35, p<.001)$. When the apology was rejected by the victim group, however, this effect disappeared ( $p=.938)$. In addition, the impact of perpetrator response on evaluation of perpetrator responders was qualified by apology quality, $F(1,239)=4.64, p=.032, \eta_{p}^{2}=.02$. Specifically, participants liked perpetrator responders more when they accepted $(M=4.92)$ rather than rejected $(M=4.34)$, an unqualified apology $(p=.001)$. This effect disappeared, however, when the apology was qualified ( $p=.755)$. No other main or interaction effects emerged, all $F \mathbf{s}<1.97, p s>.163$. 


\section{References}

Alperin, A., Hornsey, M. J., Hayward, L. E., Diedrichs, P. C., \& Barlow, F. K. (2014). Applying the contact hypothesis to anti-fat attitudes: Contact with overweight people is related to how we interact with our bodies and those of others. Social Science \& Medicine, 123, 37-44.

Barlow, F. K., Louis, W. R., \& Hewstone, M. (2009). Rejected! Cognitions of rejection and intergroup anxiety as mediators of the impact of cross-group friendships on prejudice. British Journal of Social Psychology, 48, 389-405.

Barlow, F. K., Louis, W. R., \& Terry, D. J. (2010). Minority report: Social identity, cognitions of rejection and intergroup anxiety predicting prejudice from one racially marginalized group towards another. European Journal of Social Psychology, 40, 805-818.

Barlow, F. K., Paolini, S., Pedersen, A., Hornsey, M.J., Radke, H.R.M., Harwood, J., Rubin, M., \& Sibley, C.G. (2012). The contact caveat: Negative contact predicts increased prejudice more than positive contact predicts reduced prejudice. Personality and Social Psychology Bulletin, 38, 1629-1643.

Barlow, F. K., Sibley, C.G., \& Hornsey, M.J. (2012). Rejection as a call to arms: Interracial hostility and support for political action as outcomes of race-based rejection in majority and minority groups. British Journal of Social Psychology, 51, 167-177.

Bennett, M., \& Dewberry, C. (1994). I've said I'm sorry, haven't I? A study of the identity implications and constraints that apologies create for their recipients. Current Psychology: Developmental Learning Personality Social, 13, 10-20.

Benoit, W.L. (1995). Accounts, excuses, and apologies: A theory of image restoration strategies. Albany, NY: State University of New York Press. 
Benoit, W.L., \& Drew, S. (1997). Appropriateness and effectiveness of image repair strategies. Communication Reports, 10, 152-163.

Brown, R., \& Čehajić, S. (2008). Dealing with the past and facing the future: Mediators of the effects of collective guilt and shame in Bosnia and Herzegovina. European Journal of Social Psychology, 38, 669-684.

Brown, R., González, R., Zagefka, H., Manzi, J., \& Čehajić, S. (2008). Nuestra culpa: Collective guilt and shame as predictors of reparation for historical wrongdoing. Journal of Personality and Social Psychology, 94, 75-90.

Darby, B. W., \& Schlenker, B. R. (1982). Children's reactions to apologies. Journal of Personality and Social Psychology, 43, 742-753.

Doosje, B., Branscombe, N. R., Spears, R., \& Manstead, A. S. R. (1998). Guilty by association: When one's group has a negative history. Journal of Personality and Social Psychology, 75, 872-886.

Exline, J. J., \& Baumeister, R. F. (2000). Expressing forgiveness and repentence: Benefits and barriers. In M.E. McCullough, K.I. Pargament, \& C.E. Thoresen. (Eds). Forgiveness: Theory, research and practice (pp. 133-155). New York: Guilford Press.

Exline, J. J., Baumeister, R. F., Bushman, B. J., Campbell, W. K., \& Finkel, E. J. (2004). Too proud to let go: Narcissistic entitlement as a barrier to forgiveness. Personality Processes and Individual Differences, 87, 894-912.

Giner-Sorolla, R. (2013). Judging passions: Moral emotions in persons and groups. Psychology Press.

Giner-Sorolla, R., Castano, E., Espinosa, P., \& Brown, R. J. (2008). Shame expressions reduce the recipient's insult from outgroup reparations. Journal of Experimental Social Psychology, 44, 519-526. 
Harth, N.S., Hornsey, M.J., \& Barlow, F.K. (2011). Emotional responses to rejection of gestures of intergroup reconciliation. Personality and Social Psychology Bulletin, 6, 815-829.

Hayes, A. F. (2009). Beyond Baron and Kenny: Statistical mediation analysis in the new millennium. Communication Monographs, 76(4), 408-420.

Herman, J. L. (1992). Trauma and recovery. New York: Basic Books.

Hornsey, M. J., \& Wohl, M. J. A. (2013). We are sorry: Intergroup apologies and their tenuous link with intergroup forgiveness. European Review of Social Psychology, 24, $1-31$.

Hupka, R.B., Jung, J., \& Silverthorn, K. (1987). Perceived acceptability of apologies, excuses, and justifications in jealousy predicaments. Journal of Social Behaviour and Personality, 2, 303-313.

Jetten, J., Spears, R., \& Manstead, A. S. R. (1996). Intergroup norms and intergroup discrimination: Distinctive self-categorization and social identity effects. Journal of Personality and Social Psychology, 71, 1222-1233.

Leach, C. W., Iyer, A., \& Pedersen, A. (2006). Anger and guilt about ingroup advantage explain the willingness for political action. Personality and Social Psychology Bulletin, 32, 1232-1245.

Leunissen, J.M., De Cremer, D., \& Reinders Folmer, C.P. (2012). An instrumental perspective on apologizing in bargaining. Journal of Economic Psychology, 32, 215222.

Luke, A. (1997). The material effects of the word: apologies, 'Stolen Children' and public discourse. Discrouse: studies in the cultural politics of education, 18, 343-368.

McCullough, M. E., Worthington, E. L., \& Rachal, K. C. (1997). Interpersonal forgiving in close relationships. Journal of Personality and Social Psychology, 73, 321-336. 
Noor, M., Shnabel, N., Halabi, S., \& Nadler, A. (2012). When suffering begets suffering: The psychology of competitive victimhood between adversarial groups in violent conflicts. Personality and Social Psychology Review, 16, 351-374.

Ohbuchi, K-I., \& Sato, K. (1994). Children’s reactions to mitigating accounts: Apologies, excuses, and intentionality of harm. The Journal of Social Psychology, 134, 5-17.

Park, B., \& Rothbart, M. (1982). Perception of out-group homogeneity and levels of social categorization: Memory for the subordinate attributes of in-group and out-group members. Journal of Personality and Social Psychology, 42, 1051-1068.

Risen, J. L., \& Gilovich, T. (2007). Target and observer differences in the acceptance of questionable apologies. Journal of Personality and Social Psychology, 92, 418-433.

Scheff, T. J. (1994). Bloody revenge: Emotions, nationalism and war. Boulder, CO: Westview Press.

Scher, S. J., \& Darley, J. M. (1997). How effective are the things people say to apologize? Effects of the realization of the apology speech act. Journal of Psycholinguistic Research, 26, 127-140.

Shnabel, N., \& Nadler, A. (2008). A needs-based model of reconciliation: Satisfying the differential emotional needs of victim and perpetrator as a key to promoting reconciliation. Journal of Personality and Social Psychology, 94, 116-132.

Shnabel, N., Nadler, A., \& Dovidio, J. F. (2014). Beyond need satisfaction: Empowering and accepting messages from third parties ineffectively restore trust and consequent reconciliation. European Journal of Social Psychology, 44, 126-140.

Shnabel, N., Nadler, A., Ullrich, J., Dovidio, J. F., \& Carmi, D. (2009). Promoting reconciliation through the satisfaction of the emotional needs of victimized and perpetrating group members: The needs-based model of reconciliation. Personality and Social Psychology Bulletin, 35, 1021-1030. 
Schönbach, P. (1990). Account episodes: The management or escalation of conflict. New York: Cambridge University Press.

Tavuchis, N. (1991). Mea Culpa: A sociology of apology and reconciliation. Stanford: Stanford University Press.

Techakesari, P., Barlow, F. K., Hornsey, M. J., Sung, B., Thai, M., \& Chak, J. L. (2015). An investigation of positive and negative contact as predictors of intergroup attitudes in the United States, Hong Kong, and Thailand. Journal of Cross-Cultural Psychology, 46, 454-468.

Wohl, M.J.A., Hornsey, M.J., \& Bennett, S.H. (2012). When group apologies succeed and fail: Intergroup forgiveness and the role of primary and secondary emotions. Journal of Personality and Social Psychology, 102, 306-322.

Wohl, M. J. A., \& Hornsey, M. J., \& Philpot, C. R. (2011). A critical review of official public apologies: Aims, pitfalls, and a staircase model of effectiveness. Social Issues and Policy Review, 5, 70-100.

Wohl, M. J. A., \& McLaughlin, K. L. (2014). Self-forgiveness: The good, the bad, and the ugly. Social Psychology and Personality Compass, 8, 422-435.

Woodyatt, L., \& Wenzel, M. (2014). A needs-based perspective on self-forgiveness: Addressing threat to moral identity as a means of encouraging interpersonal and intrapersonal restoration. Journal of Experimental Social Psychology, 50, 125-135.

Zaiser, E., \& Giner-Sorolla, R. (2013). Saying sorry: Shifting obligation after conciliatory acts satisfies perpetrator group members. Journal of Personality and Social Psychology, 105, 585-604. 
Table 1.

Items and response details for scales from Studies 1-4

\section{Moral Image}

(Studies 1-4)

Note. All response scales from $1=$ strongly disagree to $7=$ strongly agree

1. The apology signaled to the international community that Australians will never make the same mistakes again

2. The apology let the international community know that we Australians take full responsibility for what happened

3. Other countries will see Australia as a fair people because of the apology

4. The apology restores the moral standing of Australians in the eyes of the international community

5. Other countries will view Australians more positively as a result of reading the apology

6. The apology will show other countries that our generation is not responsible for what happened to The Stolen Generations (Studies 2-3)/Nitin Garg and other Indian victims (Studies 1 and 4)

7. People in other countries will support the Australian government's apology

8. People in other countries will see Australians as more moral because of this apology

9. After reading this apology I think others will perceive Australians as moral

10. After reading this apology I think others will perceive Australians' behavior as appropriate

11. After reading this apology I think the international community will perceive Australians as an ethical people

12. The apology made me feel proud

13. The apology made me feel moral

14. The apology made me feel fair

\section{Evaluations of Perpetrator/Victim Responders}

(Studies 3-4)

Note. All response scales from $1=$ not at all to $7=$ very much

1. How much do you think you would like the Australian/Indian/Aboriginal people whose responses you saw?

2. How much do you think you would hate the Australian/Indian/Aboriginal people whose responses you saw? (reverse scored)

3. How much do you think you would trust the Australian/Indian/Aboriginal people whose responses you saw?

\section{Willingness to Reconcile}

(Studies 1-4)

Note. All response scales from $1=$ strongly disagree to $7=$ strongly agree

1. The apology increases my willingness to act for promoting reconciliation between Indians/Aboriginal people and Australians 
2. The apology increases my willingness to express good will towards Indian/Aboriginal people

3. The apology creates a better image of Indian/Aboriginal people in my eyes

4. The apology makes me feel optimistic about future relations between Indian/Aboriginal people and Australian people

5. The apology attests to the good intentions of Australian people

6. The apology increases the proximity between Indians/Aboriginal people and Australians

7. The apology makes me perceive Indian/Aboriginal people as humans, just like Australians

8. The apology increases my willingness to learn about Indian/Aboriginal culture

9. The apology decreases tension between Indian/Aboriginal people and Australians

10. The apology improves the atmosphere between Indians/Aboriginal people and Australians

\section{Perceived Reasons for Rejection (Study 4)}

Root: "Why do you think Indians/Australians reacted this way to the apology?"

1. Because they thought that the apology was: too weak (1) to (7) too strong

2. Because they thought that the apology was: not enough (1) to (7) too much

3. Because they thought that the apology was: not apologetic enough (1) to (7) too apologetic

4. Because they believed a country should not take responsibility for the actions of an individual (1=strongly disagree to $7=$ =strongly agree)

5. Because they believed an apology was not necessary (1=strongly disagree to $7=$ strongly agree)

6. Because they thought that the apology should be accompanied by monetary compensation (1=strongly disagree to 7=strongly agree; reverse scored)

7. Because they wanted more (1=strongly disagree to $7=$ strongly agree; reverse scored) 
Table 2.

Means (and standard deviations): Study 2.

\begin{tabular}{lcccc}
\hline & \multicolumn{2}{c}{ Unqualified Apology } & \multicolumn{2}{c}{ Qualified Apology } \\
\cline { 2 - 5 } & $\begin{array}{l}\text { Perpetrator } \\
\text { Acceptance }\end{array}$ & $\begin{array}{c}\text { Perpetrator } \\
\text { Rejection }\end{array}$ & $\begin{array}{c}\text { Perpetrator } \\
\text { Acceptance }\end{array}$ & $\begin{array}{c}\text { Perpetrator } \\
\text { Rejection }\end{array}$ \\
\hline Moral image & $4.84(1.07)$ & $4.40(1.04)$ & $4.65(1.00)$ & $3.77(1.00)$ \\
$\begin{array}{l}\text { Willingness to } \\
\text { reconcile }\end{array}$ & $4.59(1.37)$ & $3.93(1.15)$ & $4.24(1.18)$ & $3.88(0.94)$ \\
\hline
\end{tabular}

Note. Standard deviations are shown in parentheses. 
Table 3.

Means (and standard deviations): Study 3.

\begin{tabular}{|c|c|c|c|c|c|c|c|c|}
\hline & \multicolumn{2}{|c|}{ Victim Acceptance } & \multicolumn{2}{|c|}{ Victim Rejection } & \multicolumn{2}{|c|}{ Victim Acceptance } & \multicolumn{2}{|c|}{ Victim Rejection } \\
\hline & $\begin{array}{l}\text { Perpetrator } \\
\text { Acceptance }\end{array}$ & $\begin{array}{l}\text { Perpetrator } \\
\text { Rejection }\end{array}$ & $\begin{array}{l}\text { Perpetrator } \\
\text { Acceptance }\end{array}$ & $\begin{array}{l}\text { Perpetrator } \\
\text { Rejection }\end{array}$ & $\begin{array}{l}\text { Perpetrator } \\
\text { Acceptance }\end{array}$ & $\begin{array}{l}\text { Perpetrator } \\
\text { Rejection }\end{array}$ & $\begin{array}{l}\text { Perpetrator } \\
\text { Acceptance }\end{array}$ & $\begin{array}{c}\text { Perpetrator } \\
\text { Rejection }\end{array}$ \\
\hline $\begin{array}{l}\text { Evaluation of } \\
\text { victim responder }\end{array}$ & $5.57(0.68)$ & $5.38(1.06)$ & $4.28(0.94)$ & $4.26(1.25)$ & $5.75(0.82)$ & $5.60(0.91)$ & $4.02(1.59)$ & $5.02(1.33)$ \\
\hline $\begin{array}{l}\text { Evaluation of } \\
\text { perpetrator } \\
\text { responder }\end{array}$ & $5.53(0.85)$ & $3.40(1.48)$ & $4.54(1.35)$ & $3.79(1.16)$ & $5.85(0.67)$ & $3.48(1.11)$ & $4.49(1.28)$ & $4.27(1.36)$ \\
\hline
\end{tabular}

Note. Standard deviations are shown in parentheses. 
Table 4.

Means (and standard deviations): Study 4.

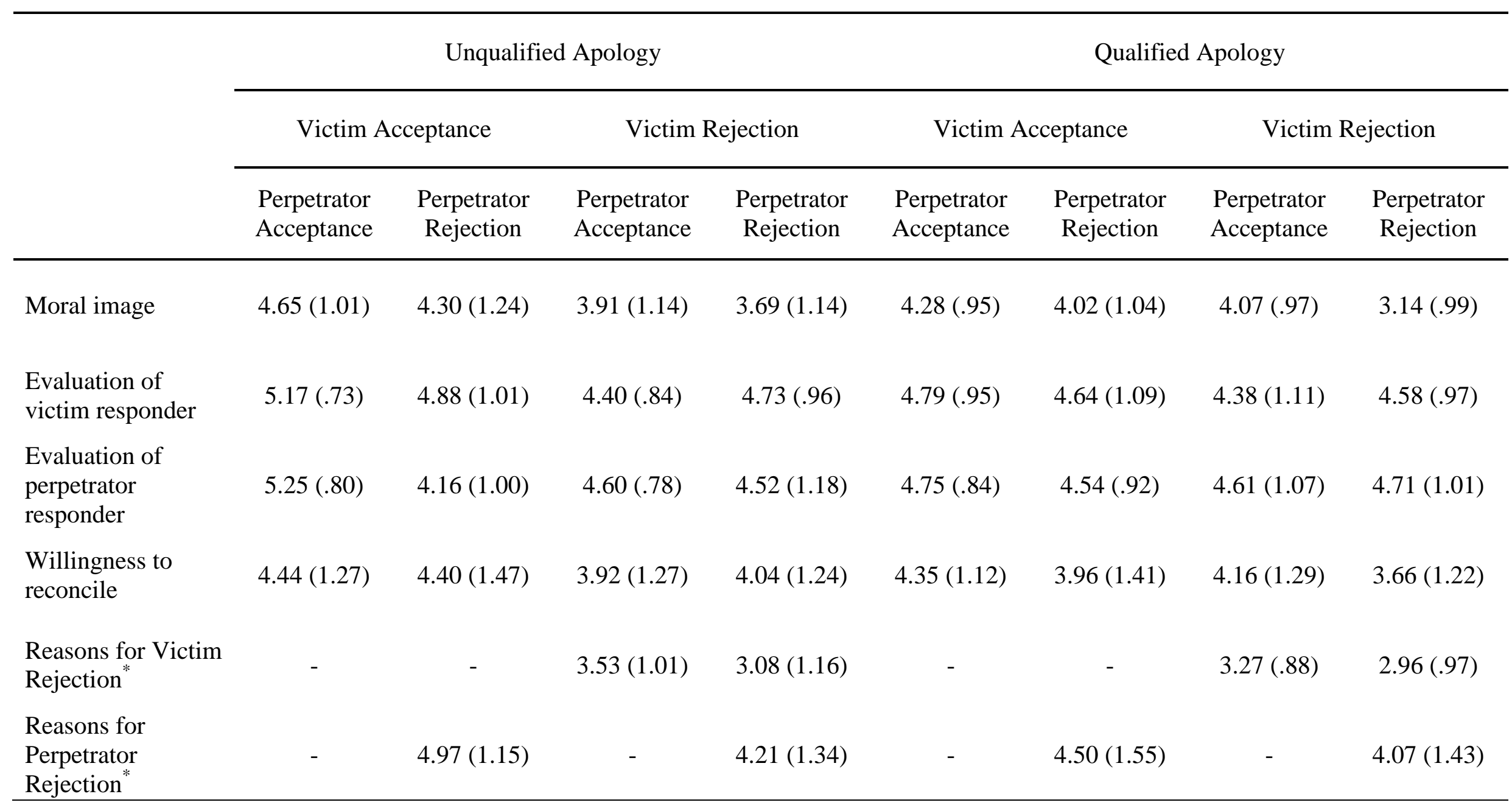




\begin{abstract}
Note. Standard deviations are shown in parentheses.
*As per Table 1, for both victim and perpetrator reasons for rejection a lower score indicates that participants thought that targets rejected the apology because it was insufficient (e.g., $1=$ too little), while a higher score indicates that participants thought that targets rejected the apology because it was too strong (e.g., $7=$ too much).
\end{abstract}


PERPETRATOR GROUPS CAN RESTORE THEIR OWN MORAL IMAGE 46

\section{List of Figures}

Figure 1. Study 1: The relationship between perpetrator group response and willingness to reconcile is mediated by moral image.

Figure 2. Study 2: The relationship between perpetrator group response and willingness to reconcile is mediated by moral image.

Figure 3. Study 3: The relationship between perpetrator and victim group response and willingness to reconcile as mediated by moral image and evaluation of apology responders.

Figure 4. Study 4: The relationship between perpetrator and victim group response and willingness to reconcile as mediated by moral image and evaluation of apology responders. 


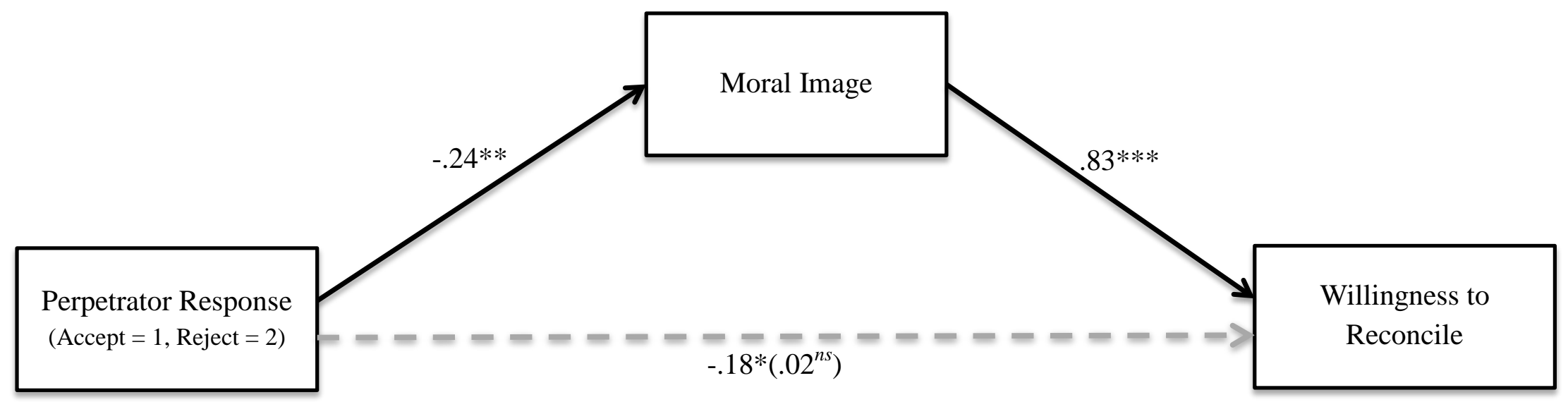

Note. ${ }^{\dagger} p<.10,{ }^{*} p<.05,{ }^{* *} p<.01,{ }^{* * *} p<.001$ 


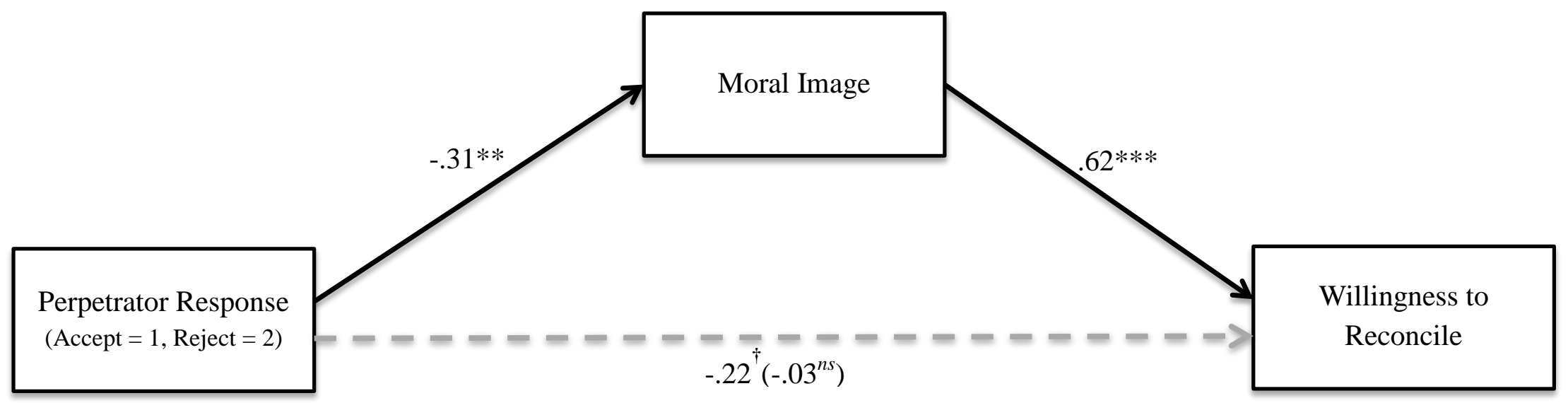

Note. ${ }^{\dagger} p<.10,{ }^{*} p<.05,{ }^{* *} p<.01,{ }^{* * *} p<.001$ 


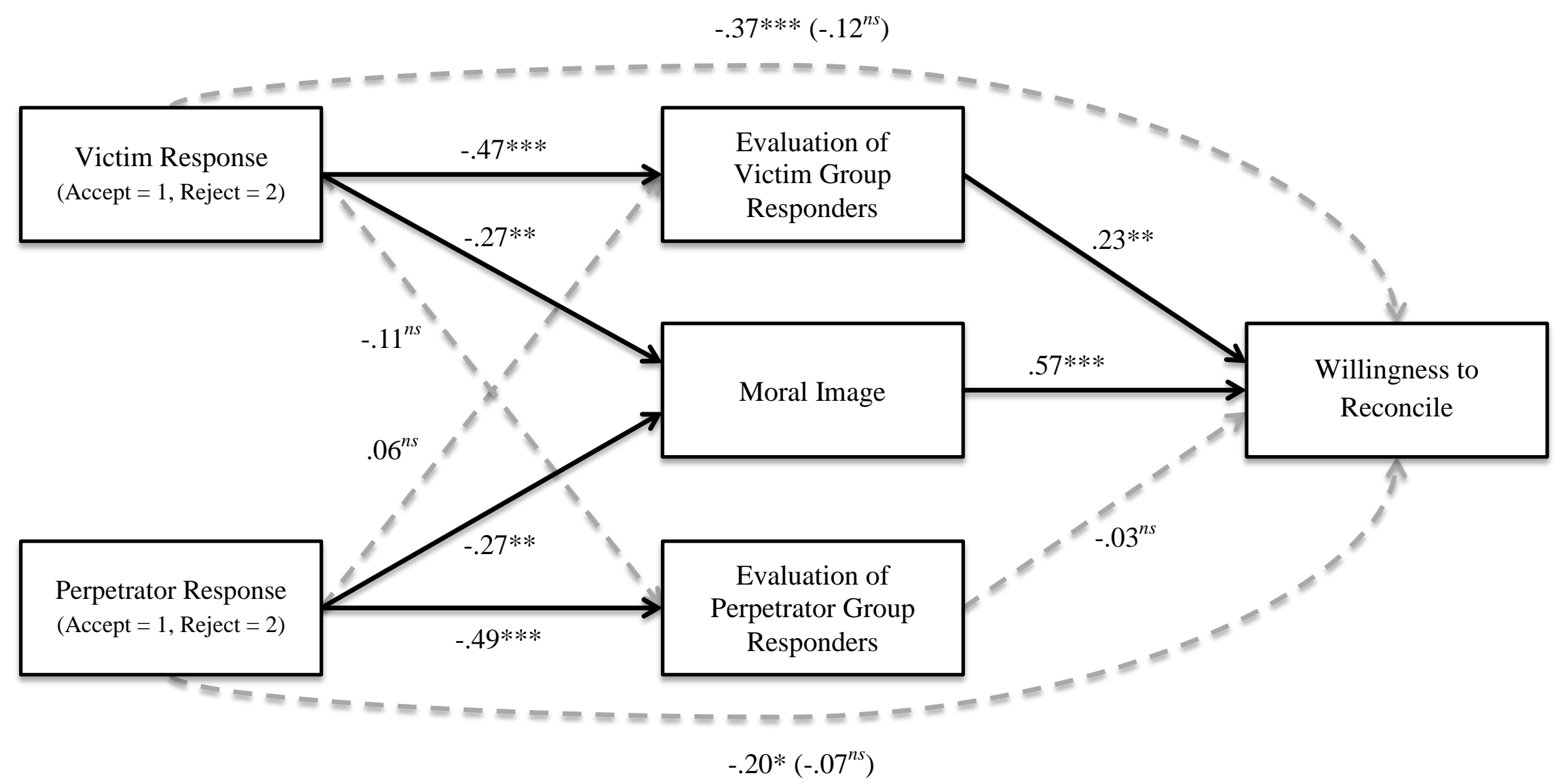

Note. ${ }^{*} p<.05,{ }^{* *} p<.01,{ }^{* * *} p<.001$ 
$-.13^{*}(.12 *)$

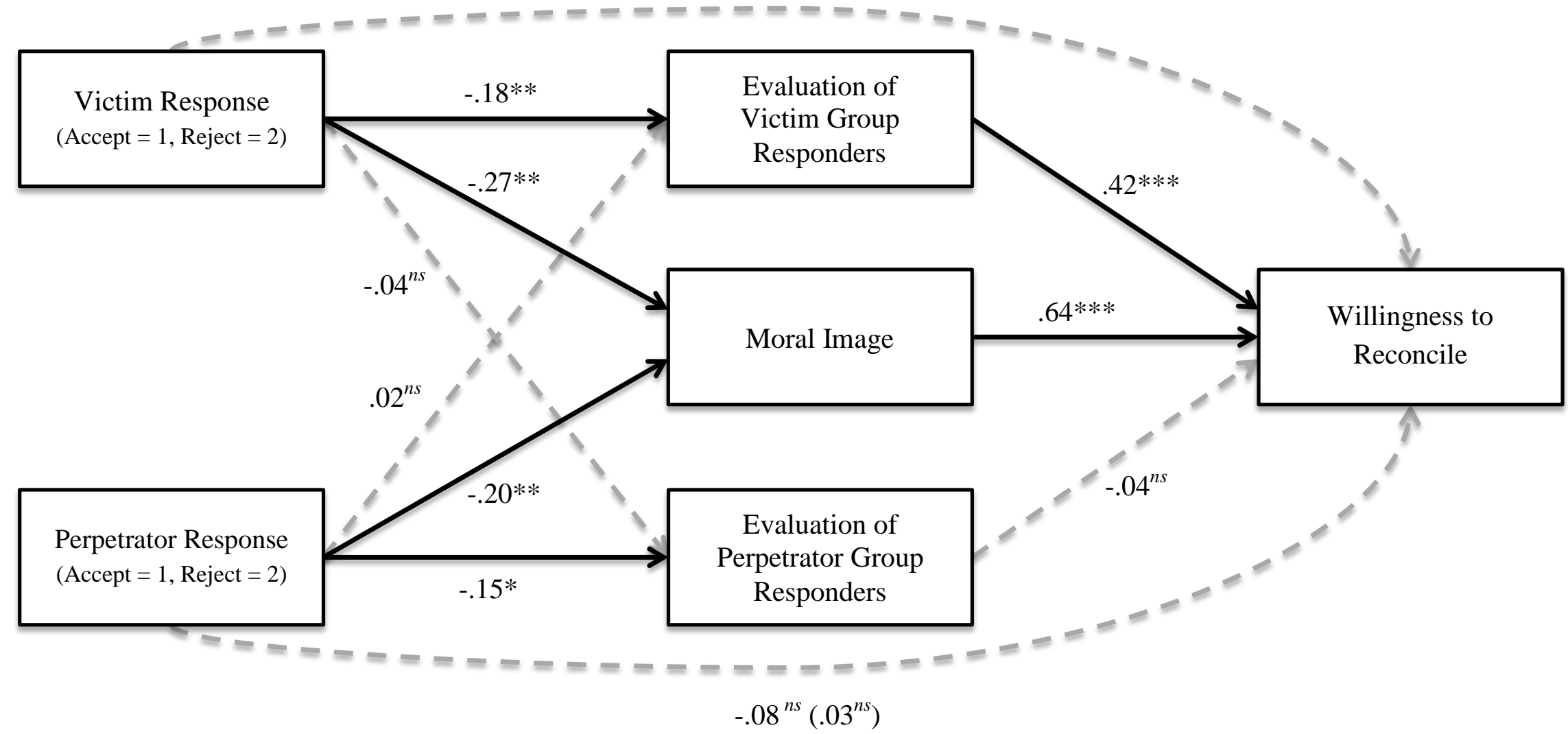

Note. ${ }^{*} p<.05,{ }^{* *} p<.01,{ }^{* * *} p<.001$ 